\title{
Hanging: A Ten-Year Retrospective Review of Malaysian Forensic Cases
}

\author{
Md Naziri SZ ${ }^{\mathrm{a}}$, Abu Bakar SN , Alias A $\mathrm{A}^{\mathrm{b}, \mathrm{c}}$, Ibrahim A ${ }^{\mathrm{b}, \mathrm{d}}$, Mohamed Swarhib DMJ', Mohd Nor F $\mathrm{F}^{\mathrm{b}}$. \\ a Jabatan Perubatan Forensik, Hospital Serdang, Jalan Puchong, 43000 Kajang, Selangor, Malaysia. \\ ${ }^{b}$ Forensic Unit, Department of Pathology, Universiti Kebangsaan Malaysia Medical Centre, Jalan Yaakob \\ Latif, Bandar Tun Razak, 56000 Kuala Lumpur, Malaysia. \\ ${ }^{c}$ Faculty of Dentistry, Universiti Sains Islam Malaysia, Tingkat 15, Menara B, Persiaran MPAJ, Jalan Pandan \\ Utama, Pandan Indah, 55100 Kuala Lumpur, Malaysia. \\ ${ }^{d}$ Faculty of Medicine, Al-Azhar University, 1 Al Mokhaym Al Daem, Gameat Al Azhar, Nasr City, Cairo \\ Governorate, Egypt.
}

\section{ABSTRACT}

Introduction: Hanging is one of the most common methods of suicide in Malaysia, and to date, there is a rise in the number of deaths by hanging among adults. The purpose of this study was to determine the pattern of hanging in Malaysia from the year 2000 till 2009. Methods: The sample comprised 108 cases received at the Universiti Kebangsaan Malaysia Medical Centre, and five parameters, namely, age, sex, racial affiliation, marital status, and medical history were studied. Results: Of the 108 cases, 56\% was reported to be Chinese. Suicide by hanging was more predominant in males (81\%), and a high number of cases were seen in age groups of 21 to 30,31 to 40 and 41 to 50 years. Of the cases studied, half of them were married, and previous history of physical and mental illness and alcohol intoxication were reported. Conclusions: In brief, this data would help the higher authorities in detecting the causes of suicide by hanging, as well as detecting the high risk groups with suicidal tendencies. In this way, suicide can be prevented and thus, the rate of suicide by hanging could be reduced in Malaysian.

KEYWORDS: Suicide, Malaysia, death, forensic, hanging.

\section{INTRODUCTION}

Hanging occurs when the strength by ligature strangulation is applied to an individual's neck as a result of the gravitational force on the body. This may result in the lack of oxygen supply to the brain (cerebral hypoxia), which may further lead to unconsciousness, and eventually death. ${ }^{1}$ Human neck has a high risk in varieties of fatal injuries due to its limited bony support and the presence of airway, spinal cord and large vessels in its small diameter. For these reasons, hanging has been chosen for execution in law sentences, and also favored as a way of suicide by the world population. $^{2}$

Corresponding author:

Assoc. Prof. Dr. Faridah Mohd Nor

Department of Pathology,

Universiti Kebangsaan Malaysia Medical Centre, Jalan Yaacob Latif, Bandar Tun Razak, Cheras, 56000 Kuala Lumpur, Malaysia

Tel No: $+603-91455368$

Email : mnfaridah@gmail.com
A study done by National Suicide Registry Malaysia (NSRM) from July until December 2007 showed that the chosen method by Malaysians males (54\%) and females (35\%) for suicide were hanging, strangulation and suffocation. ${ }^{3}$ This was in agreement with a study done by Henderson et al. (2005), whereby the majority of suicides at the St. Pancras Coroner's Court, London were by hanging. ${ }^{4}$ However, in India and US, it was the second leading method after intoxication. ${ }^{5-8}$

In Western Australia, the peak prevalence was in males between 15 and 35 years of age (58\%) with a history of psychiatric illness (33\%). ${ }^{1}$ About $93 \%$ of deaths by hanging were suicide with 14 were accidental hanging and one homicidal hanging. In Lithuania from 1993 to 2002, the most common suicide was by hanging. ${ }^{9}$ Over the years, suicidal hanging has increased significantly from $89.4 \%$ to 91.7\% in men, and from $77.3 \%$ to $82.6 \%$ in females particularly, among girls aged between 10 to 19 years. ${ }^{9}$ 
There has been past reports of suicide by hanging from all around the world, but scanty has been published in the Malaysian context. Hence this study was performed, and it is presumed that the results of this study would be beneficial for the authorities in understanding the causes and eventually detecting the groups that is high risk in suicidal tendency generally, and committing suicide by hanging, specifically. Therefore, suicide could be prevented and the rate of suicide and suicide by hanging in Malaysia could be reduced.

\section{METHODS}

This study was a retrospective study of cases received at the mortuary of the UKM Medical Centre from the year 2000 until 2009. A total number of 124 hanging cases were received during the whole study period. Cases without documentation were excluded from the study. Only cases with proper and completed documentation were taken as a sample, leaving only 108 cases to be analyzed. The ages of the deceased were between 14 to 77 years old, comprised males and females from three racial groups, Malay, Chinese and Indian. The data collected was demographic data, including sex, race, age, marital status and medical history, which were presented in descriptive form.

\section{Statistical analysis}

All the data were then tabulated and analyzed by means of descriptive statistical analysis.

\section{RESULTS}

\section{Demographic data}

The total number of hanging fatalities was 124, which represented about $4.8 \%$ of cases in a ten-year period. Nevertheless, only 108 cases were collected in this study, in which all of the cases were classified as suicide. The remaining cases were excluded for reasons of lack of documentation. Results showed that the highest peak reached was documented in 2007, followed by 2009, 2001 and 2006. (Figure 1) Deaths by hanging were predominantly males by a ratio of male to female of $3: 1$, except for the year 2001, where females predominated (Figure 2).

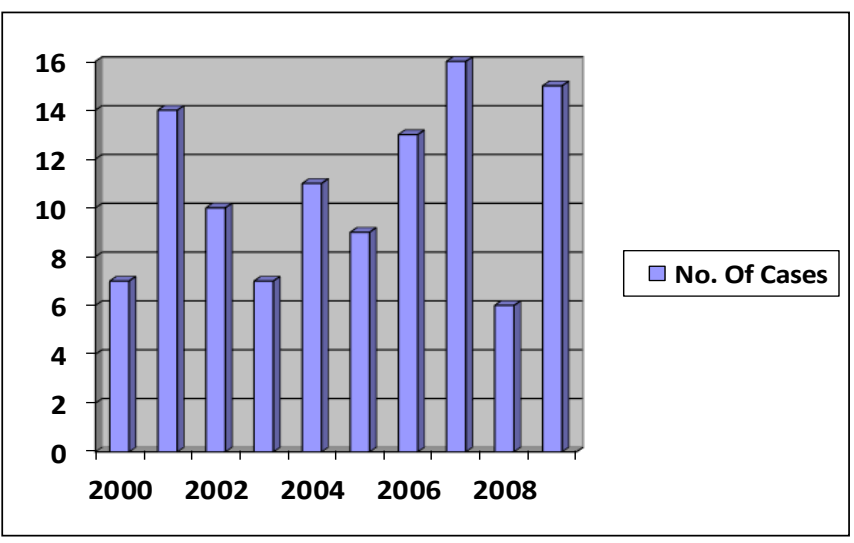

Figure 1: Cases of deaths by hanging in Forensic Unit, UKMMC (2000-2009).

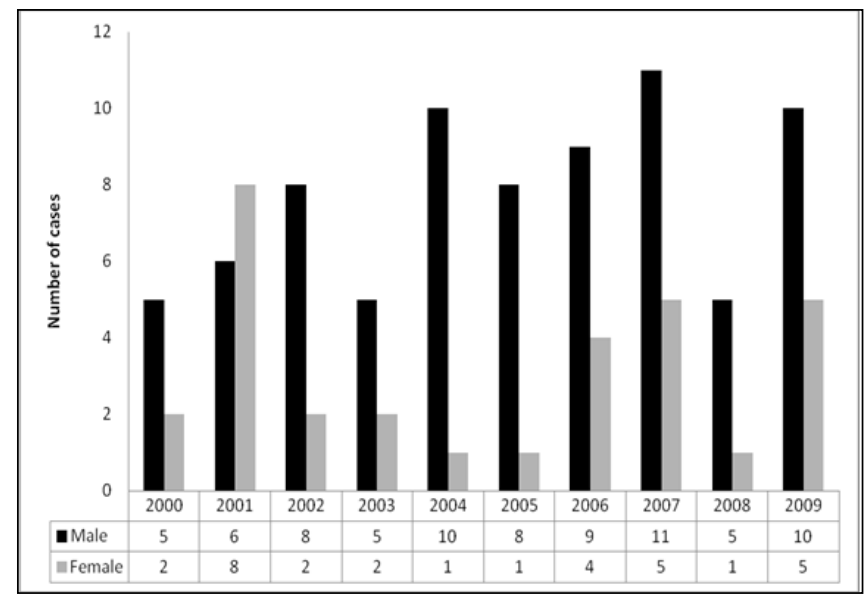

Figure 2: Distribution of cases according to sex.

By hanging, 79\% were Malaysians and the remaining were foreigners (Indonesian, Indian, Myanmar). Among Malaysians, 56\% were Chinese, 15\% Indians and $5 \%$ Malays. In this study, high number of cases were seen in age groups of 21 to 30,31 to 40 and 41 to 50 years in both males and females. In half of these cases, the victims were married. The majority of deaths by hanging showed no significant life turning points or previous history of other illnesses. However, there was a previous history of significant life events, which may have contributed to their decision to commit suicide. Other problems documented were psychiatric and physical illness, substance abuse or combinations of any of the events (Figure 3).

\section{DISCUSSION}

Death by hanging constituted $4.8 \%$ of all forensic autopsies carried out in UKMMC. A research conducted by National Suicide Registry Malaysia in 2007 showed that the favored suicide methods among the Malaysians were by hanging, strangulation and suffocation, ${ }^{3}$ and this finding was comparable to a study in St. Pancras Coroner's Court, London, UK, 


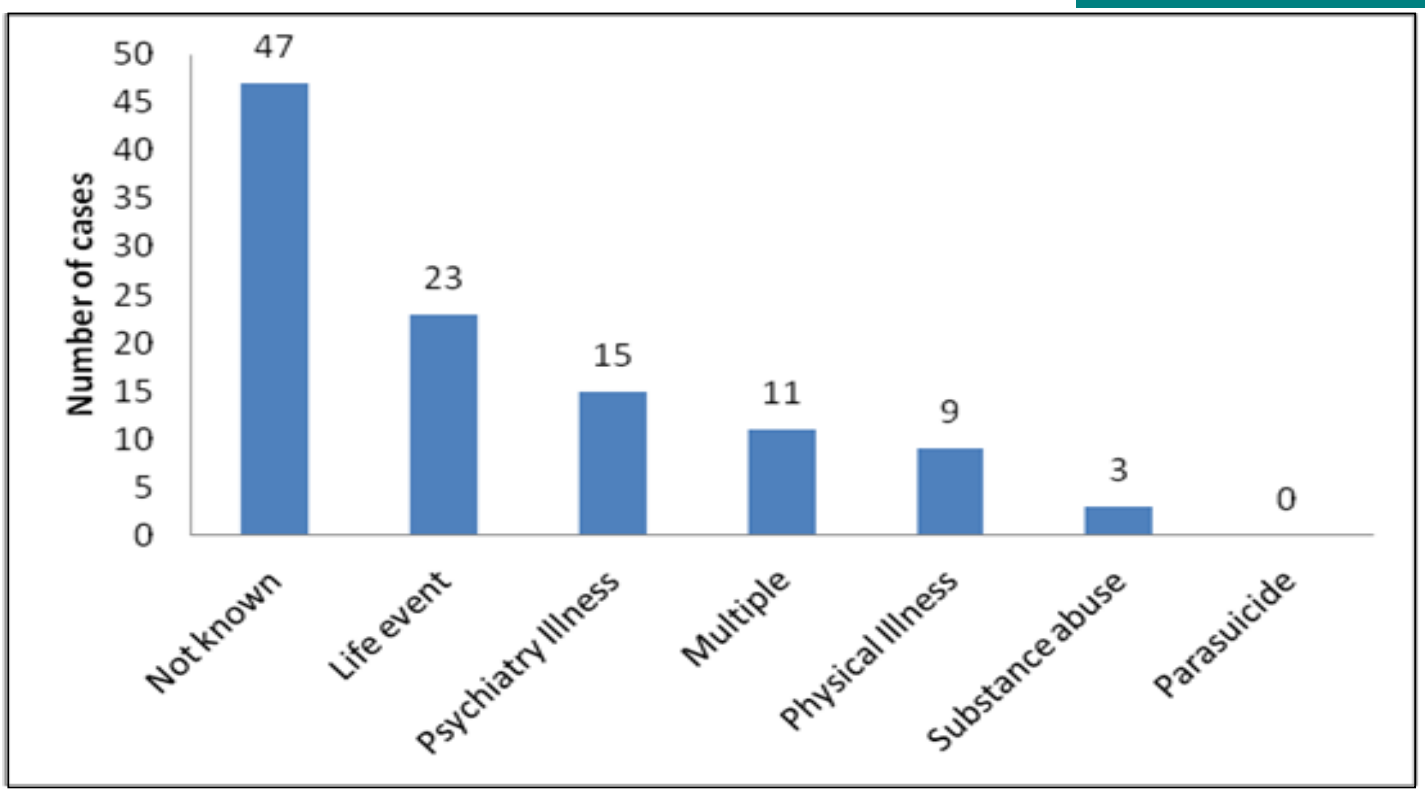

Figure 3: Distribution of medical history in deaths by hanging.

which showed that the majority of suicides was caused by hanging. ${ }^{4}$

Suicidal hanging in Malaysia was predominant in males $(81 \%)$ compared to that in females $(19 \%)$. This was in agreement with a study in Cardiff, in which males constituted approximately $60 \%$ of cases. ${ }^{10}$ High suicidal rate in men was attributed to the fact that males were more subjected to temptations, challenges, stresses and strains in life than in females. ${ }^{11,12}$ Nevertheless, these figures were in contrast to a study, which showed a higher incidence of hanging with women $(40 \%)$ in Denmark, ${ }^{13}$ in London and Northern Ireland. ${ }^{14,15}$

A study in England and Wales showed that divorced and widowed men and women have higher rates of suicide than those, who were married. ${ }^{16}$ Studies showed that marriage contributed to better health both physically and emotionally. Scientists have understood why married men have better health compared to their peers, who are single, divorced or widowed. ${ }^{17}$

According to the previous study, ${ }^{3}$ the highest rate for all major racial groups was hanging as the method was easily accessible, and usually has a high success rate. Malaysia is a multi-racial country, with 3 major races that consists of Malay, Chinese and India. ${ }^{18}$ In this study, statistics shows that Chinese commits suicide more frequently than the Indians and Malays. Majority of Chinese in Malaysia follows Buddhism, which promotes an attitude of acceptance in the face of adversity. ${ }^{20}$ However, they grant suicide in order to protect one's dignity. ${ }^{21}$ Islam on the other hand, is very definite in prohibiting suicide among its believers. ${ }^{19}$

Generally, adults aged between 21 to 50 years accounted for $73.1 \%$ of cases, in which the peak age was between 41 to 50 years old. The youngest age recorded was 14 years old, while the oldest being 77 years old. A study in Turkey revealed that the age group of 20 to 29 years has the greatest number of suicides in both males and females. ${ }^{28}$ Similarly, the third decade showed a maximum number of suicides in South India. ${ }^{29}$ Adults from this age group might suffer from a great amount of stress, which contributed to their decisions in ending their own lives. ${ }^{1,12}$ On the other hand, the current study revealed that the number of cases was the lowest $(4.6 \%)$ in the age group of 11 to 20 years. In both developed and developing countries, the suicide rate among young people appeared to be rising. ${ }^{30}$ Peer pressure and emotional issues were the triggering factors. Among the elderly, suicidal hanging was not restricted to males only.

With the advance of medical facilities and technologies, lifespan of individual has increased. However, the quality of life has yet to follow. This has led to a high rate of suicide by hanging in late middle-aged and elderly persons. Loss of companion, reduce in health quality, restriction in mobility and being highly dependent to others have contributed to the decisions to end their lives. ${ }^{31}$

Literature showed that recent life events could play a major role in someone's determination for suicide. ${ }^{32,33}$ of 61 known medical history cases, 23 
cases have history of previous life events, including problems in schools, financial constraints and marital issues. In 15 cases (13.9\%), there were history of pre-existing psychiatric illness comprised schizophrenia and depression. However, these figures might be miscalculated due to the unwillingness of witnesses to share information to the police and doctors. ${ }^{34}$

Mental disorders (mood disorders, conduct disorders, substance abuse and disruptive disorders), previous suicidal attempts, family history of suicidal behaviour, and stressful life events are risk factors of suicide for both sex. ${ }^{35}$ About 11 cases were reported with multiple medical histories, and having more than one medical illness could be considered as particularly high risk. ${ }^{36}$ The presence of physical illness was reported in 9 cases such as diabetes, hypertension, HIV, ischaemic heart disease, pulmonary tuberculosis and fibrosing alveolitis. Others had cancer, namely prostate cancer, breast cancer and nasopharyngeal carcinoma. According to NSRM reports in 2007, individuals with such illnesses might conclude that their life was meaningless due to lack of physical functions, disturbance in social life and unbearable pain, which will finally lead to suicide. ${ }^{3}$

\section{CONCLUSION}

A thoroughly planned and comprehensive rehabilitation program is warranted to identify forewarning indicators in suicide, and helps to prevent suicide. Appropriate education of medical staff and mass media will help in increasing awareness on the suicide cases, which will eventually, assort methods to prevent suicide by hanging in the future.

\section{CONFLICT OF INTEREST}

The authors have declared that there are no conflicts of interest in conducting this study.

\section{ACKNOWLEDGEMENTS}

The authors gratefully acknowledge Prof Srijit Das from the Anatomy Department of UKMMC for the technical support provided in writing this article.

\section{REFERENCES}

1. Cooke CT, Cadden GA, Margolius KA. Death by hanging in Western Australia. Pathology 1995; 27: 268-72.

2. Montalban D. Untitled Prezi: Capital punishment around the world: The United States, China and Iran. 2013. Available at: https://prezi.com/0ymvchgaixdy/untitledprezi/. Accessed December 12, 2016.

3. National Suicide Registry Malaysia, Preliminary Report July-December 2007.

4. Henderson JP, Mellin C, Patel F. Suicide - A statistical analysis by age, sex and method. J Clin Forensic Med 2005; 12: 309-307.

5. Ojima T, Nakamura Y, Detels R. Comparative study about methods of suicide between Japan and the United States. J Epidemiol 2004; 19(9): 823-9.

6. Joseph A, Abrajam S, Muliyil JP, Prasad J, Minz $\mathrm{S}$, Abraham VJ, Jacob KS. Evaluation of suicide rates in rural India using verbal autopsies, 1994 -1999. BMJ 2003; 326(7399):1121-2.

7. Wiesner G. Suicidal methods-a comparison between East and West Germany.

Epidemiological, forensic and sociomedical aspects. Bundesgesundheitsblatt

Gesundheitsforschung Gesundheitsschutz 2004; 47(11):1095-106.

8. Shields LB, Hunsaker DM, Hunsaker JC. Suicide: a ten-year retrospective review of Kentucky medical examiner cases. J Forensic Sci 2005; 50 (3): 613-7.

9. Starkuviene $\mathrm{S}$, Kalediene R, Petrauskiene J. Epidemic of suicide by hanging in Lithuania: Does socio-demographic status matter? Journal of Royal Public Health 2006; 120: 769-775.

10. James R, Silcocks P. Suicidal hanging in Cardiffa 15 year retrospective study. Forensic Sci Int 1992; 56: 167-75.

11. Stack S. Suicide: a 15 year review of the sociological literature. Part II: modernization and social integration perspectives. Suicide Life Threat Behav 2000; 24: 362-74.

12. Girard C. Age, gender and suicide: a cross national analysis. Am Sociol Rev 1993; 58: 55374.

13. Simonsen J. Patho-anatomic findings in neck structures in asphyxiation due to hanging; a survey of 80 cases. For Sci Int 1988; 38: 83-91.

14. Bowen DA. Hanging - A review. Forensic Sci Int 1982; 20: 247-9.

15. Davison A, Marshall TK. Hanging in Northern Ireland - A survey. Med Sci Law 1986; 26: 23-8. 
16. Charlton J. Trends in patterns in suicide in England and Wales. International Journal of Epidemiology 1995; 24:Suppl. 1, S45- S52.

17. Anonymous. Harvard's Men's Health Watch: Marriage and men's health. Available at: http: / / www.health.harvard.edu/ newsletter_article/marriage-and-menshealth. Assessed December 21, 2016.

18. Bee OJ, Lockard CA, Ahmad Z, Leinbach TR. Encyclopaedia. Encyclopaedia Brittanica: Malaysia. Last updated: 23/9/2016.

19. Ong S, Yeoh KL. Suicidal behaviour in Kuala Lumpur. In Kok LP, Morris, Maniam: Ethnicity and Suicidal Behaviour in Malaysia. 1992.

20. Kok LP. Suicidal behaviour in Singapore. In L. P. Kok \& W. Tseng (Eds.), Suicidal behaviour in the Asia-Pacific region. Singapore: Singapore University Press. 1992. p. 176-198.

21. Hussain, H., \& Hyman, N. W. Family psychopathology and childhood experience of the parasuicides admitted to University Hospital, Kuala Lumpur. Asian J Psychiatr 1994; 4: 9-16.

22. Uzun I, Buyuk Y, Gurpinar K. Suicidal hanging: Fatalities in Istanbul Retrospective analysis of 761 autopsy cases. J Forensic Leg Med 2007; 14: 406-409.

23. Kanchan T, Menezes RG. Suicidal hanging in Manipal, South India- victim profile and gender differences. J Forensic Leg Med 2008;15(8):493-6.

24. Eddlesto M, Rezvi S M H, Hawton K. Deliberate Self Harm in Sri Lanka; an overlook tragedy in the developing world. BMJ 1998; 7151: 133135.

25. Anon. Suicide in Canada: Update of the Report of the Task Force on Suicide in Canada (ed.) Ottawa: Health Canada. 1994.

26. Heikkinen ME, Isomets ET, Henrikson MM. Suicide in major depression. Am J Psychiatry 1994; 151: 530-36.

27. Foster T, Gillespie K, McClelland R, Patterson C. Risk factors for suicide independent of DSM - Ill - R Axis I disorder: Case-control psychological autopsy study in Northern Ireland. British Journal of Psychiatry 1999; 175: 175-179.

28. Barraclough B, Bunch J, Nelson B, Sainsbury P. A hundred cases of suicide: clinical aspects. Br J Psych 1974; 125: 355-73

29. Beautrais AL, Collings SCD, Ehrhardt $P$, Henare K. Suicide Prevention: A review of evidence of risk and protective factors, and points of effective intervention. (ed.) Wellington: Ministry of Health, 2005.

30. Druss B, Pincus H. Suicidal Ideation and Suicide Attempts in General Medical Illnesses. Arch Intern Med 2000; 160:1522- 1526. 
